Review / Meta-analyses

\title{
Functional outcome and social cognition in bipolar disorder: Is there a connection?
}

\author{
Maria Vlad ${ }^{\mathrm{a}}$, Delphine Raucher-Chénée,b,*, Audrey Henry ${ }^{\mathrm{a}, \mathrm{b}}$, Arthur Kaladjian ${ }^{\mathrm{a}, \mathrm{b}, \mathrm{c}}$ \\ a Psychiatry Department, University Hospital, Reims, France \\ ${ }^{\mathrm{b}}$ Cognition, Health \& Society (C2S - EA 6291) Laboratory, University of Reims Champagne-Ardenne, Reims, France \\ ${ }^{\mathrm{c}}$ Faculty of Medicine, University of Reims Champagne-Ardenne, Reims, France
}

\section{A R T I C L E I N F O}

\section{Article history:}

Received 1 December 2017

Received in revised form 30 April 2018

Accepted 2 May 2018

Available online 19 May 2018

\section{Keywords:}

Bipolar disorder

Social cognition

Functional outcome

Social functioning

\begin{abstract}
A B S T R A C T
Background: Interest in social cognition in bipolar disorder (BD) has increased considerably over the past decade, with studies highlighting major impairments, especially in mental state reasoning, even during euthymia. A causal relationship between social cognition deficits and social functioning has already been established in individuals with schizophrenia, but there is still little information about links between social cognition and social functioning in $\mathrm{BD}$. Our aim was therefore to review the relationship between functional outcome and social cognition in patients with BD.

Methods: We conducted a systematic review of the literature. Relevant articles were identified through literature searches in the MEDLINE/PubMed, EBSCOHost and Google Scholar databases for the years 2000-2017, using the keywords bipolar,social cognition, theory of mind, mentalizing, emotion recognition, emotion processing, and functioning. A total of 20 studies met our inclusion/exclusion criteria.

Results: We found that functioning was significantly correlated with three domains of social cognition (ToM, emotion processing, and attribution bias). Twelve of 13 studies reported a correlation with emotion processing, but a correlation with ToM was only found in three of the 11 studies that assessed it. Six studies found an effect of depressive symptoms on emotion processing and no significant association was found with manic symptomatology.

Conclusions: To the best of our knowledge, the present review is the first to specifically explore the relationship between social cognition and social functioning in patients with BD. This exploration is of interest, as it enhances current understanding of this disorder and, by so doing, should improve patient outcomes.
\end{abstract}

(c) 2018 Elsevier Masson SAS. All rights reserved.

\section{Introduction}

Bipolar disorder (BD) is reportedly the sixth leading cause of disability worldwide [1]. It is a chronic psychiatric disease characterized by considerable mood instability, with periods of expansive mood alternating with periods of depressive mood. It causes severe behavioral, relational, social and familial problems [2,3].

It has already been established that patients with BD have fewer social interactions and more restricted social networks than healthy individuals [4]. The psychosocial disability resulting from BD is extensive, and encompasses multiple domains, including work and social interactions, independent living in the community, family adjustment, mortality, and quality of life [5]. In a review conducted

\footnotetext{
* Corresponding author at: Pôle de Psychiatrie Adulte, CHU de Reims - HRD, Avenue du Généra Koenig, 51092 Reims Cedex, France.

E-mail address: draucherchene@chu-reims.fr (D. Raucher-Chéné).
}

by MacQueen et al. [6], 30-60\% patients with BD had detectable levels of social impairment, occurring in both occupational and social domains, whether or not they had interepisode symptoms. The factors that contribute to psychosocial impairment in BD may be interlinked, creating an effect of functional decline [7].

Among the most common clinical factors associated with impaired social functioning are episodes of depression [8] or subsyndromal depressive symptoms [9,10]. These have been significantly associated with impaired work, family and social life [8]. By contrast, changes in the severity of mania or hypomania have not been consistently associated with variations in social functioning [11].

Research on the functional outcome in BD has uncovered several factors besides mood symptoms that exacerbate psychosocial disability over the course of the illness, including genetics, illness severity, stress, anxiety, and cognitive impairment [7]. Some studies have found a specific relationship between poor functional outcomes in patients with BD and aspects of cognitive impairment 
[5,12]. Cognitive performances (executive function, verbal learning and memory, attention, processing speed) have been associated with patients' level of functioning in both the short and long term $[13,14]$. In a longitudinal study, Burdick et al. [12] concluded that cognitive impairment should be treated as a different dimension from residual or persistent depressive features. They also advocated regular assessments of cognitive status as well as mood symptoms in future studies of functional outcome.

One aspect of cognition that is particularly worth exploring is social cognition. Social cognition is defined as the aspect of cognition that is dedicated to processing social information for adaptive functioning [15]. More specifically, it refers to an intricate set of higher-order neuropsychological domains that allow for adaptive behaviors in response to others [16]. Four dimensions are usually included in this construct: theory of mind (ToM), emotion processing, social perception and social knowledge, and attribution bias [17]. In BD, impairments with medium effect sizes are observed in social cognition $[18,19]$. Significant ToM dysfunctions, but with modest effect sizes, have been observed in $\mathrm{BD}$, in both remitted and subsyndromal patients, with a greater deficit during acute episodes [18].

There has been abundant research on social cognition in schizophrenia. These studies have revealed that patients exhibit a significant ToM impairment with large effect sizes [20,21]. This impairment remains significant regardless of the type of task used, and persists even during remission $[20,22,23]$. Various areas of social cognition (emotion perception, social perception, attributional style, ToM) have been identified as independent correlates of social functioning in schizophrenia [24], and a causal relationship between social cognition deficits and social functioning has been already established in patients [25]. By contrast, there is a surprising dearth of studies assessing the relationship between baseline social cognition and concurrent baseline social functioning in BD populations.

We set out to provide a comprehensive overview of the relationship between social functioning and social cognition in patients with BD. To the best of our knowledge, this was the first systematic review of the available literature on the subject. The aims were a) to gain an overview of the association between social cognition and functional outcome in $\mathrm{BD}, \mathrm{b})$ to explore if this association is present at the different clinical phases of $\mathrm{BD}$, and $\mathrm{c}$ ) to identify possible gaps within the present literature and directions for future research.

\section{Materials and methods}

\subsection{Search strategy and selection criteria}

We conducted a systematic review and data extraction of the published literature in accordance with Preferred Reporting Items for Systematic Reviews and Meta-analyse (PRISMA) guidelines [26], to identify studies of the relationship between social cognition and social functioning in BD. Relevant articles were identified through literature searches in the MEDLINE/PubMed, EBSCOHost, Scopus and Google Scholar databases and, as the exploration of social cognition in bipolar disorder has been developed in the early 2000s, we restricted our search strategy to the period between January 2000 and October 2017. We used eight keywords (social cognition, theory of mind, mentalizing, emotion recognition, emotion processing, social perception, social knowledge, and attribution bias) for the social cognition component, and two keywords (social functioning, functional outcome, quality of life) for the functioning component; associated with the term bipolar. The reference lists of the articles we retrieved were also individually explored to look for other relevant reports. We personally contacted the authors of two articles in order to obtain publications that were not available through our university library.

\subsection{Inclusion and exclusion criteria}

We only selected articles that were available in the English language. Their titles and abstracts were reviewed to determine whether they met the following additional methodological criteria: (1) BD I or BD II population; (2) at least one social cognition task and one functioning scale; and (3) search for a possible connection between social cognition and functioning in BD. As shown in Fig. 1, we initially identified 339 titles and abstracts, but only 20 studies met all the eligibility criteria and were thus included in our review.

\subsection{Data extraction}

After duplicate publications were excluded, the first author (MV) screened all the remaining abstracts. In case of indistinctness, full texts were consulted. Two independent reviewers (MV, DRC) read the full text and all ineligible papers were excluded. Disagreements between the reviewers were discussed and resolved during consensus meetings. Information for each eligible study was extracted and tabulated. Extracted data included sample characteristics, method for assessing BD diagnosis, BD type, relevant measures, and main findings. The extraction process was completed independently by MV and checked by DRC.

\subsection{Brief listing of the tasks and scales used}

\subsubsection{Social cognition tasks}

The different tasks used in the studies we included are listed in Table 1. Facial emotion recognition was explored through sets of pictures of facial expressions that had to be labeled. The most commonly used ToM tasks were Reading the Mind in the Eyes Test (RMET; [27]) and the Faux Pas Recognition Test [28]. In the RMET, individuals are instructed to look at a series of photographs of just the eye region of the face, and decide which word out of four best describes what the person in the photo is thinking or feeling. Faux pas recognition involves recognizing faux pas in a series of short stories. We also noted various versions of false-belief and intention tasks. Only two studies assessed attribution bias. Participants first had to complete a questionnaire describing various situations, after which they were asked to devise an explanation for why each situation had occurred. Social perception and social knowledge were not specifically assessed.

\subsubsection{Functional outcome scales}

The most consistently used scales were the Global Assessment of Functioning (GAF; from DSM-IV-TR; [29]), the Functioning Assessment Short Test (FAST; [30]), and the Social Adjustment Scale Self-Report (SAS-SR; [31]).

The GAF is used to assess patients' overall functional status across psychological, social and occupational domains, via a single anchored measure. With a range extending from positive mental health to severe psychopathology, it is intended to be more of a generic scoring system than a diagnosis-specific one. It has the advantage of being simple to use [32].

Another well attested functioning assessment tool is the FAST [30], which was used in four of the 19 articles included in the review, either on its own or with the GAF. The FAST scale probes six functional domains: financial, interpersonal, leisure, autonomy, occupational and cognitive functioning. The six separate dimensional scores are summed to produce an overall functionality score.

The SAS-SR [31] assesses a broad range of social domains, focusing on more specific subjects such as work/school role, social/ leisure activities, relationship with extended family, marital role, parental role and membership of a family unit. 

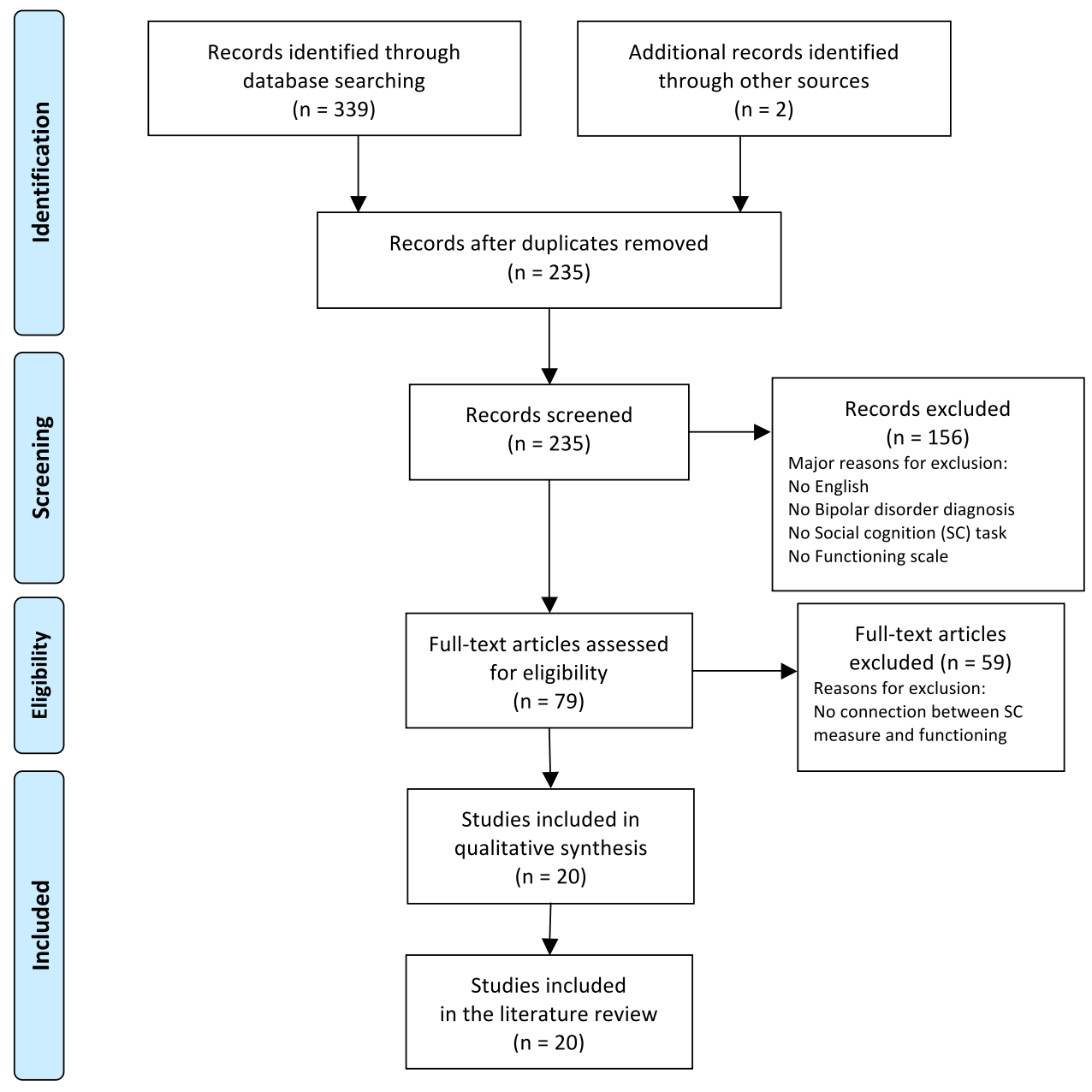

Fig. 1. Flowchart of the literature search.

Table 1

Sociocognitive domains and tests.

\begin{tabular}{|c|c|c|}
\hline Sociocognitive domain & Tests & Numbers of studies \\
\hline \multirow[t]{9}{*}{ Theory of mind (reported by 12 studies) } & Reading the Mind in the Eyes Test (RMET) & 7 \\
\hline & Faux Pas Recognition Test & 4 \\
\hline & Hinting Task & 2 \\
\hline & Story comprehension & 1 \\
\hline & False-belief stories of the Picture Sequencing Task & 1 \\
\hline & Cartoon comprehension & 1 \\
\hline & Cognitive and Emotional Perspective-Taking Task (CEPTT) & 1 \\
\hline & Interpersonal Perception Task- 15 (IPT-15) & 1 \\
\hline & Interpersonal Reactive Index (IRI) & 1 \\
\hline \multirow[t]{12}{*}{ Emotion perception and processing (reported by 13 studies) } & Pictures of Facial Affect (POFA) & 1 \\
\hline & FEEST & 2 \\
\hline & Facial Emotion and Identification Test (FEIT) & 2 \\
\hline & Facial Emotion and Discrimination Test (FEDT) & 3 \\
\hline & Penn Emotion Recognition-40 (ER-40) & 3 \\
\hline & Facially Expressed Emotion Labeling (FEEL) test & 2 \\
\hline & The Mayer-Salovey-Caruso Emotional Intelligence Test (MSCEIT) & 2 \\
\hline & DANVA-2 Facial Emotion Recognition Task & 1 \\
\hline & Chicago Pediatric Emotional Acuity Task (Chicago PEAT) & 1 \\
\hline & Emotion processing test & 1 \\
\hline & Facial expression recognition task & 1 \\
\hline & Assessing Emotions Scale - Emotion Perception (AES-EP) & 1 \\
\hline Attributional bias (reported by 2 studies) & Ambiguous Intentions Hostility Questionnaire (AIHQ) & 2 \\
\hline
\end{tabular}


Similar scales, like the Life Functioning Questionnaire (LFQ; [33]), Social and Occupational Functioning Assessment Scale (SOFAS; [34]) and Bipolar Disorder Functioning Questionnaire [35], were used in a number of the articles we included.

Both the Quality of Life in Bipolar Disorder (QoL.BD; [36]) and the World Health Organization Quality of Life-BREF (WHOQOLBREF; The WHOQOL Group; [37]) are subjective self-report scales. The QoL.BD assesses 10 core domains (physical, sleep, mood, cognition, leisure, social, spirituality, finances, self-esteem, and independence and identity) and two optional domains (education and work). The WHOQOL-BREF consists of 26 items scored in four domains: physical, psychological, social relationships, and environment.

\section{Results}

In total, 20 studies yielded results on the relationship between social cognition and functional outcome in either euthymic or symptomatic patients with BD-I or BD-II. Nine studies were conducted in euthymic patients with $\mathrm{BD}$. The 11 remaining studies included symptomatic, subsyndromal and euthymic patients. Only one study compared patients across different phases of the disease. Two studies compared patients with BD-I or BD-II. Table 2 summarizes the study designs and the main findings for social cognition and functional outcome in patients with BD.

\subsection{Functioning and clinical variables}

The GAF was the most used scale to assess functioning, as it was measured in 13 of the 19 articles included in the present review. The FAST, the QoL.BD and the WHOQOL-Bref were used in four articles. The SAS-SR was used as a measure of functionality in three of the 19 studies. The LFQ was used in two studies and the other measures (SOFAS, Bipolar Disorder Functioning Questionnaire) in one study each. As expected, functional outcome scores were significantly impaired in patients with $\mathrm{BD}$, compared with healthy controls (HC) [38-41].

With regard to social functioning, we noted significantly poorer overall functioning among patients with BD than among HC [41,42]. Mood symptoms seem to be the determining factor for social functioning during acute episodes [43], with more severe mood symptoms being associated with poorer social functioning $[38,39,44,45]$. Depressive symptomatology was associated with lower functional outcome across the domains of mood, cognition, leisure, sociability, spirituality, self-esteem, independence, identity, work and the overall score, as well as with GAF scores [39].

Neither the GAF nor the QoL.BD overall scores correlated significantly with clinical variables like age, sex, age at illness onset or diagnosis, subsyndromal manic symptoms (Young Mania Rating Scale, YMRS), employment status or psychosis history $[39,40,45]$.

\subsection{Functioning and emotion processing}

Overall, patients with BD displayed significantly impaired recognition, identification and discrimination of facial emotions, compared with HC [44-47]. They performed particularly poorly on happiness and disgust recognition $[48,49]$.

Twelve of thirteen studies reported a connection between functional outcome and emotion processing (i.e., identification of specific emotions, emotion regulation) in euthymic and symptomatic patients. For example, the GAF score correlated positively with the recognition of facial expressions of disgust, fear and happiness in patients with BD $[48,50]$. Emotion discrimination impairment was significantly correlated with a lower FAST score, showing that deficits in facial emotion discrimination have a negative impact on participation in social activities, as well as on daily activities and hobbies [47]. In one of the studies, intentionality bias and emotion recognition together explained around $50 \%$ of the variance in the GAF score [39]. Deficits in tasks assessing the understanding and management of emotions (MSCEIT strategic area) were also related to a greater social functioning impairment, particularly for the autonomy, occupational and relationships FAST domains [51,52]. Correct recognition of expressions of happiness was associated with better scores on the physical and psychological dimensions of the WHOQOL-BREF $[48,49]$. The ability to identify fear was correlated with higher quality of life ratings, even after accounting for demographic factors and current mood symptoms. The same results were found for self-reported emotion perception after controlling for executive function and demographic factors. This effect, however, was only relevant to wellbeing-not to occupational prestige [40]. Subjective wellbeing scores were significantly related to lower current depressive symptoms and higher emotion perception scores [40].

The influence of mood symptomatology on the link between emotion processing and functional outcome was unclear. When depressive symptomatology was included in the statistical analysis (partial correlations or regression analysis), six studies found an effect of depressive symptoms [38,39,45,48,51,53]. The correlation between emotion recognition and GAF scores lost significance, mainly owing to the MADRS score [48]. Van Rheenen and Rossell [39] found a mediation effect of depression symptomatology on emotion regulation, as well as on subjective and objective psychosocial functioning. However, three studies did not report any effect of depressive symptoms $[40,47,50]$. In Fulford's study, fear recognition was a significant predictor of QoL.BD scores. Depression history and sex each significantly contributed to the explained variance, whereas current depression did not.

Only one study directly compared the emotion recognition and discrimination performances of patients with BD across different phases of the disease. This showed that during mood remission, accurate emotion discrimination had a positive effect on participation in social and daily activities and hobbies, while correct emotion identification had a positive impact on taking initiatives and feeling self-sufficient [43]. In both depressive and manic episodes, no significant correlation was found between Facial Emotion Identification Test (FEIT) and Facial Emotion Discrimination Test (FEDT) scores and domains of social functioning [43].

\subsection{Functioning and theory of mind}

In the studies we included, the most consistently used task was the RMET, with discrepant results for accuracy in participants with BD compared with controls. Lower scores were reported by some of these studies (54), but most of them failed to reach significance $[41,42,44,50]$. Similarly, some (but not all) RMET task results correlated positively with functioning [41,55]. In Caletti et al. [41], GAF scores were positively correlated with performances on the RMET task. In Purcell et al. [55], an exploratory analysis revealed that lower RMET response times predicted greater overall life functioning difficulties within the home duties and work duties subscales for the BD group. However, the other studies failed to find a positive correlation between RMET scores and functioning. No significant correlations were found between RMET and either overall functioning or any of the six functional dimensions assessed by the FAST scale in Barrera et al.'s study [42]. Nor was RMET performance associated with any domain of the SAS-SR in any of the analyses [54]. The RMET did not contribute to variance beyond neurocognitive impairments, and no other significant associations were found between social functioning and measures of social cognition [50].

GAF scores were positively correlated with performances on faux pas tasks in Caletti et al. [41], and Lahera et al. [45]. In Lahera 
Table 2

Overview of the studies included in reverse chronological order.

\begin{tabular}{|c|c|c|c|c|c|}
\hline Article & Sample & Mood state & SC tasks & $\begin{array}{l}\text { Functioning } \\
\text { Scale }\end{array}$ & Findings \\
\hline $\begin{array}{l}\text { Aparicio } \\
\text { et al. [51] }\end{array}$ & $\begin{array}{l}\text { BD-I }(n=60) \\
\text { mean age: } 44.9 \\
(11.6) \text { yrs } \\
\text { HC }(n=60) \\
\text { Mean age: } 42.2 \\
(10.3) \text { yrs }\end{array}$ & $\begin{array}{l}\text { HDRS: } 2.7 \text { (1.97) } \\
\text { YMRS: } 0.8 \text { (1.6) }\end{array}$ & MSCEIT & FAST & $\begin{array}{l}\text { Significant correlation between FAST total score and } \\
\text { MSCEIT strategic area score (understanding and managing } \\
\text { emotions) }(r=0.31 ; p=.016) \text {. } \\
\text { Residual depressive symptomatology explains a } 9.1 \% \text { of } \\
\text { the variance in functional outcome and the MSCEIT } \\
\text { strategic area score explained an additional increase of } \\
8.6 \%(F(1,57)=5.97 ; p=.018) \text {. }\end{array}$ \\
\hline $\begin{array}{l}\text { Varo et al. } \\
\text { [52] }\end{array}$ & $\begin{array}{l}\text { BD-I }(n=134) \\
\text { mean age: } 45.05 \\
(12.63) \text { yrs }\end{array}$ & $\begin{array}{l}\text { HDRS LP: } 4.8(2.4) \\
\text { HDRS NP: } 3.6(2.5) \\
\text { HDRS HP: } 2.6(2.4) \\
\text { YMRS LP: } 2.1(1.9) \\
\text { YMRS NP: } 1.7(1.9) \\
\text { YMRS HP: } 1.9(2.3)\end{array}$ & $\begin{array}{l}\text { MSCEIT } \\
\text { ( } 3 \text { groups according to } \\
\text { MSCEIT scores: Low } \\
\text { Performance (LP), Normal } \\
\text { Performance (NP) and High } \\
\text { Performance (HP) }\end{array}$ & FAST & $\begin{array}{l}\text { Greater functional impairment was related to lower } \\
\text { MSCEIT scores. } \\
\text { The LP group showed higher impairment in global } \\
\text { functional outcome and four domains of the FAST } \\
\text { (autonomy, occupational and relationships). }\end{array}$ \\
\hline $\begin{array}{l}\text { Lahera } \\
\text { et al. [38] }\end{array}$ & $\begin{array}{l}\text { BD }(n=46) \\
\text { mean age: } 38.6 \\
(10.63) \text { yrs } \\
\text { HC }(n=50) \\
\text { mean age: } 43.4 \\
(13.6) \text { yrs }\end{array}$ & $\begin{array}{l}\text { HDRS }<8: 50 \% \\
8<\text { HDRS }<14: \\
41.3 \% \\
\text { HDRS }>14: 8.7 \% \\
\text { YMRS }<8: 65.2 \% \\
8<\text { YMRS }<14: \\
34.8 \%\end{array}$ & $\begin{array}{l}\text { AIHQ } \\
\text { FEIT } \\
\text { FEDT } \\
\text { ER-40 } \\
\text { Hinting Task }\end{array}$ & GAF & $\begin{array}{l}\text { For HDRS } \leq 7, \text { significant bivariate correlation between } \\
\text { GAF and HDRS scores }(r=-0.427, p=.047) \text {, AIHQ Total } \\
(r=-0.478, p=.028) \text {, AIAQ Intentionality }(r=-0.480 \\
p=.028), \text { ToM }(r=0.418, p=.053) \text {, and ER40 }(r=0.645 \\
p=.001) .\end{array}$ \\
\hline $\begin{array}{l}\text { Wegbreit } \\
\text { et al. [46] }\end{array}$ & $\begin{array}{l}\text { BD-I }(n=66) \\
\text { mean age: } 16.7 \\
(4.7) \text { yrs } \\
\text { HC }(n=87)\end{array}$ & $\begin{array}{l}\text { YMRS: } 6.0(4.5) \\
\text { CDRS/HDRS: } \\
\text { Adolescents: } 29.1 \\
\text { (11.6) Adults: } 5.2\end{array}$ & $\begin{array}{l}\text { DANVA facial emotion } \\
\text { recognition task }\end{array}$ & GAF & $\begin{array}{l}\text { BD participants' overall functioning had a significant effect } \\
\text { on facial recognition errors, even after accounting for } \\
\text { participants' age and FSIQ. }\end{array}$ \\
\hline
\end{tabular}
mean age: $17.9(4.7) \quad(4.4)$ yrs

Vierck et al. $\mathrm{BD}(n=36$; BD-I: $\quad$ MADRS $<6: 53 \%$

[44] $n=28$, BD-II: $n=8) \quad 7<$ MADRS $<19$ : mean age: $40.8 \quad 30 \%$ (11.6) yrs $\quad 20<$ MADRS $<34$ : $\mathrm{HC}(n=40) \quad 14 \%$ mean age: $36.2 \quad$ Mixed symptoms: (11.3) yrs $3 \%$

Facial expression recognition SAS scale task RMET

MADRS: 11.82

(10.08)

YMRS: 6.22 (5.47)

False-belief stories of

Picture Sequencing Task

Emotion processing task

Difficulties in Emotion

Regulation Scale

GAF

QoL.BD
Van $\quad \operatorname{BD}(n=51)$

Rheenen mean age: 38.44

and (12.89) yrs

Rossel HC $(n=52)$

[39] mean age: 33.98 (14.28) yrs

WHOQOL-BREF

GAF

YMRS: $1.1(1.4)$

Siedentopf mean age: 38.4

et al. [48] (12.89) yrs

$\mathrm{HC}(n=50)$

mean age: 33.98

(14.28) yrs

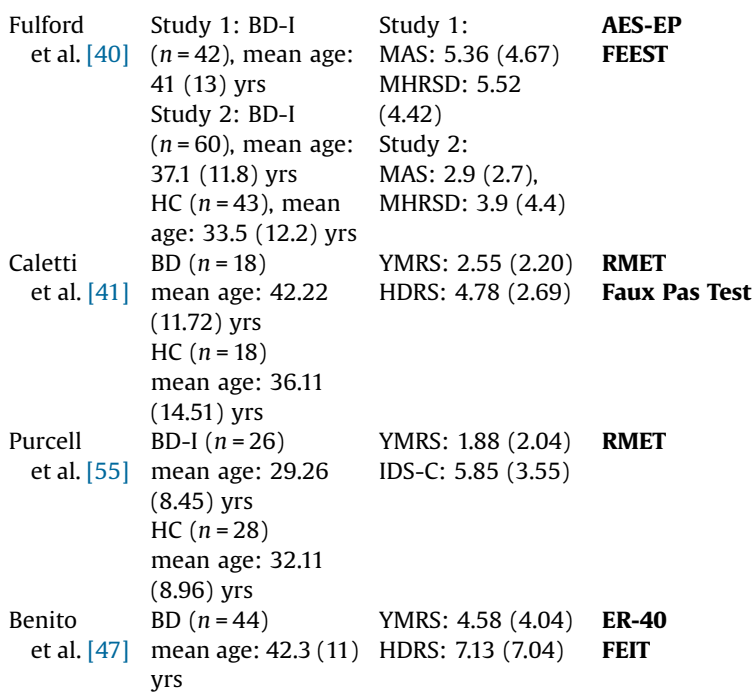

Study 1:

MAS: 5.36 (4.67)

MHRSD: 5.52

(4.42)

Study 2:

MAS: 2.9 (2.7),

MHRSD: 3.9 (4.4)

YMRS: 2.55 (2.20) RMET

HDRS: 4.78 (2.69) Faux Pas Test

YMRS: 1.88 (2.04) RMET

IDS-C: 5.85 (3.55)

AES-EP

FEEST

(1)

HDRS: $7.13(7.04)$ FEIT

HC functioned better than BD participants, but emotional processing still did not affect social functioning. 
Table 2 (Continued)

\begin{tabular}{|c|c|c|c|c|c|}
\hline Article & Sample & Mood state & SC tasks & $\begin{array}{l}\text { Functioning } \\
\text { Scale }\end{array}$ & Findings \\
\hline & $\begin{array}{l}\mathrm{HC}(n=48) \\
\text { mean age: } 45.73 \\
(12.2) \text { yrs }\end{array}$ & & $\begin{array}{l}\text { FEDT } \\
\text { Hinting Task }\end{array}$ & & \\
\hline $\begin{array}{l}\text { Aydemir } \\
\text { et al. [43] }\end{array}$ & $\mathrm{BD}(n=109)$ & $\begin{array}{l}\text { Remission: } n=70 \\
\text { Manic episode: } \\
n=20 \\
\text { Major depressive } \\
\text { episode: } n=19\end{array}$ & $\begin{array}{l}\text { FEIT } \\
\text { FEDT }\end{array}$ & $\begin{array}{l}\text { Bipolar Disorder } \\
\text { Functioning } \\
\text { Questionnaire }\end{array}$ & $\begin{array}{l}\text { During remission, the FEDT score had a positive effect on } \\
\text { participation in social activities }(t=2.430, p<.05) \text {, and } \\
\text { daily activities and hobbies }(t=2.601, p<.05) \text {, whereas } \\
\text { FEIT had a positive impact on initiative taking and feeling } \\
\text { self-sufficient ( } t=2.341, p<.05) \text {. }\end{array}$ \\
\hline $\begin{array}{l}\text { Barrera } \\
\text { et al. [42] }\end{array}$ & $\begin{array}{l}\text { BD }(n=12 ; \text { BD-I: } \\
n=7, \text { BD-II: } n=5) \\
\text { mean age: } 48.2 \\
(11.2) \text { yrs } \\
\text { HC }(n=12) \\
\text { mean age: } 46.04 \\
(12.3) \text { yrs }\end{array}$ & $\begin{array}{l}\text { YMRS: } 2.25(2.73) \\
\text { HDRS-17: } 3.80 \\
(2.47)\end{array}$ & $\begin{array}{l}\text { RMET } \\
\text { Faux Pas Test }\end{array}$ & FAST & $\begin{array}{l}\text { No significant correlations were found between RMET or } \\
\text { Faux Pas Test scores and overall functioning. }\end{array}$ \\
\hline $\begin{array}{l}\text { Cusi et al. } \\
\text { [54] }\end{array}$ & $\begin{array}{l}\text { BD }(n=25 ; \text { BDI-I: } \\
\text { 17, BDI-II: } 7 \text {, not } \\
\text { specified: } 1) \\
\text { mean age: } 45.2 \\
(10.8) \text { yrs } \\
\text { HC }(n=25) \\
\text { mean age: } 44.2 \\
(11.8) \text { yrs }\end{array}$ & $\begin{array}{l}\text { HDRS: } 8.1(6.2) \\
\text { YMRS: } 2.0(2.0)\end{array}$ & $\begin{array}{l}\text { RMET } \\
\text { IPT15 }\end{array}$ & $\begin{array}{l}\text { SAS-SR } \\
\text { GAF }\end{array}$ & $\begin{array}{l}\text { The IPT- } 15 \text { was negatively associated with the Marital Role } \\
\text { domain of the SAS-SR (rho }=-0.41, p<.03) \text {. A significant } \\
\text { negative association was also found between the IPT- } 15 \\
\text { Intimacy subscale and the SAS-SR Work/School Role } \\
\text { domain (rho }=-0.32, p<.04) \text {. RMET performance was not } \\
\text { associated with any domain of the SAS-SR in any analysis } \\
(p>.05) \text {. }\end{array}$ \\
\hline $\begin{array}{l}\text { Lahera } \\
\text { et al. [53] }\end{array}$ & $\begin{array}{l}\text { BD }(n=37 ; \text { BD-I: } \\
n=28, \text { BD-II: } n=5 \\
\text { SAD: } n=4) \\
\text { mean age: } 38.7 \\
(11.6) \text { yrs } \\
\text { HC }(n=32) \\
\text { mean age: } 44.2 \\
(12.6) \text { yrs }\end{array}$ & $\begin{array}{l}\text { HDRS: } 8.42(7.38) \\
\text { YMRS: } 4.47(4.94)\end{array}$ & AIHQ & $\begin{array}{l}\text { GAF } \\
\text { FAST }\end{array}$ & $\begin{array}{l}\text { Global functioning (GAF) correlated significantly with } \\
\text { AIHQIS ( } p=.005) \text {, AIHQAS }(p=.027) \text {, and AIHQAB }(p=.02) \text {. } \\
\text { Correlations did not reach statistical significance for the } \\
\text { FAST scale. }\end{array}$ \\
\hline $\begin{array}{l}\text { Lahera } \\
\text { et al. [45] }\end{array}$ & $\begin{array}{l}\text { BD }(n=39) \\
\text { mean age: } \\
\text { low FAST: } 48.5 \\
(15.8) \text { yrs high } \\
\text { FAST: } 45.1(13.7) \text { yrs }\end{array}$ & $\begin{array}{l}\text { HDRS: } \\
\text { low FAST: } 3.8(3.2) \\
\text { high FAST: } 1.1(1.6) \\
\text { YMRS: } \\
\text { low FAST: } 1.3(2.1) \\
\text { high FAST: } 1.3(1.9)\end{array}$ & $\begin{array}{l}\text { Faux Pas Recognition } \\
\text { Test } \\
\text { Emotion recognition } \\
\text { test }\end{array}$ & $\begin{array}{l}\text { FAST } \\
\text { GAF }\end{array}$ & $\begin{array}{l}\text { Significant correlation between subsyndromal depressive } \\
\text { symptoms }(r=0.39, p=.01) \text {, performance on the Faux Pas } \\
\text { test }(r=-0.32, p=.04) \text { and Asarnow test }(r=0.42, p=.01) \\
\text { and, as expected, GAF scores }(r=-0.52, p<.001) \text {. A } \\
\text { hierarchical regression analysis shows that verbal social } \\
\text { cognition deficit is associated with low social functioning } \\
\text { and subsyndromal depressive symptoms can significantly } \\
\text { influence this association. }\end{array}$ \\
\hline $\begin{array}{l}\text { Martino } \\
\text { et al. [50] }\end{array}$ & $\begin{array}{l}\text { BD-I }(n=45) \text { mean } \\
\text { age: } 37.2(10.2) \text { yrs } \\
\text { BD-II }(n=36) \\
\text { mean age: } 42.9 \\
(10.4) \text { yrs } \\
\text { HC }(n=34) \\
\text { mean age: } 39.7 \\
(12.5) \text { yrs }\end{array}$ & $\begin{array}{l}\text { YMRS: } \\
\text { BD-I: } 1.0(1.2) \\
\text { BD-II: } 1.2(1.6) \\
\text { HDRS: } \\
\text { BD-I: } 2.1(2.0) \\
\text { BD-II: } 2.1(2.0)\end{array}$ & $\begin{array}{l}\text { Faux Pas Recognition } \\
\text { Test RMET EKMAN-60 }\end{array}$ & GAF & $\begin{array}{l}\text { Psychosocial functioning correlated positively with facial } \\
\text { recognition of disgust }(r=0.40, p<.001) \text { and fear }(r=0.28 \text {, } \\
p=.012) \text { in patients with BD. }\end{array}$ \\
\hline $\begin{array}{l}\text { Hoertnagl } \\
\text { et al. [49] }\end{array}$ & $\begin{array}{l}\text { BD-I }(n=47) \\
\text { mean age: } 42.2 \\
(10.2) \text { yrs } \\
\text { HC }(n=45) \\
\text { mean age: } 39.9 \\
(6.2) \text { yrs }\end{array}$ & $\begin{array}{l}\text { MADRS: } 3.0(2.3) \\
\text { YMRS: } 1.3(1.5)\end{array}$ & $\begin{array}{l}\text { FEEL } \\
\text { EER }\end{array}$ & $\begin{array}{l}\text { WHOQOL-BREF } \\
\text { GAF }\end{array}$ & $\begin{array}{l}\text { Correct recognition of happiness (FEEL) correlated } \\
\text { positively with most QoL domains }(r=0.45, p=.045 \text { for } \\
\text { both global and physical QoL; } r=0.47, p=.024 \text { for } \\
\text { psychological QoL). }\end{array}$ \\
\hline $\begin{array}{l}\text { Cusi et al. } \\
\text { [57] }\end{array}$ & $\begin{array}{l}\text { BD }(n=20 ; \text { BD-I: } \\
n=14, \text { BD-II: } n=6) \\
\text { mean age: } 43.0 \\
(8.9) \text { yrs } \\
\text { HC }(n=20) \\
\text { mean age: } 40.1 \\
(15.1) \text { yrs }\end{array}$ & $\begin{array}{l}\text { HDRS: } 11.3(6.9) \\
\text { YMRS: } 3.0(2.1)\end{array}$ & IRI & $\begin{array}{l}\text { GAF } \\
\text { SAS-SR }\end{array}$ & $\begin{array}{l}\text { Lower scores on the IRI Empathic Concern subscale } \\
\text { showed reduced functioning on the Social/Leisure } \\
\text { Activities subscale of the SAS-SR }(r=-0.34, p<.05) \text {. } \\
\text { Significant positive correlations were found between the } \\
\text { IRI Personal Distress subscale and global social functioning } \\
(r=0.48, p<.01) \text {, Work/School Role }(r=0.38, p<.05) \text {, } \\
\text { Social/Leisure Activities }(r=0.47, p<.01) \text { and Relationship } \\
\text { with Extended Family }(r=0.34, p=.05) \text {. }\end{array}$ \\
\hline $\begin{array}{l}\text { Olley et al. } \\
\text { [56] }\end{array}$ & $\begin{array}{l}\text { BD-I }(n=15) \\
\text { mean age: } 39.20 \\
(11.83) \text { yrs } \\
\text { HC }(n=13) \\
\text { mean age: } 40.77 \\
(13.42) \text { yrs }\end{array}$ & $\begin{array}{l}\text { HDRS: } 3.00(3.87) \\
\text { YMRS: } 1.46(1.56)\end{array}$ & $\begin{array}{l}\text { Story comprehension } \\
\text { Cartoon comprehension }\end{array}$ & $\begin{array}{l}\text { SOFAS } \\
\text { LFQ }\end{array}$ & $\begin{array}{l}\text { ToM was not significantly correlated with any outcome } \\
\text { measures of social and occupational functioning. }\end{array}$ \\
\hline
\end{tabular}

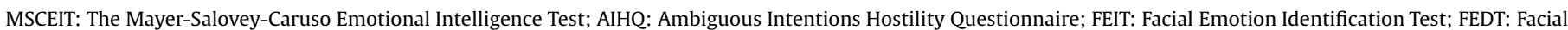

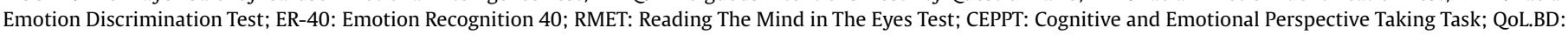

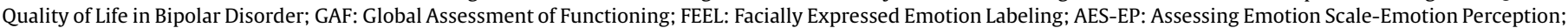

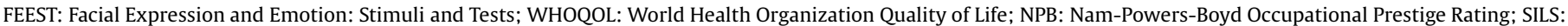

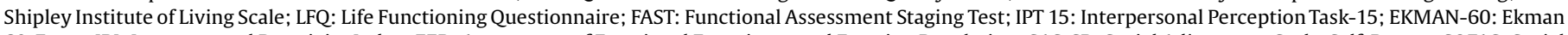

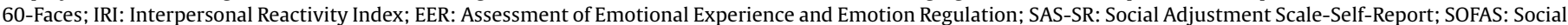
and Occupational Functional Assessment Scale. 
et al. [45], patients with a low FAST score performed significantly more poorly on the faux pas test, and this result was not confounded by either education level or attention deficit. It should, however, be noted that subsyndromal depressive symptoms can significantly influence this association [53]. No association between scores on the faux pas task and social functioning was found by Martino et al. [50] or Barrera et al. [42].

Scores on the Hinting Task, ToM story task, and ToM and nonToM cartoon tasks were not significantly correlated with functioning [38,47,56].

In summary, an association between functioning and ToM was only found in three of the 12 studies that assessed it. Only Lahera et al.'s [38] study found that the association between a verbal social cognition deficit and low social functioning was significantly influenced by subsyndromal depressive symptoms.

\subsection{Functioning and other social cognition tasks}

Patients with BD were found to have significantly impaired attributional style in both of the studies that used the Ambiguous Intentions Hostility Questionnaire (AIHQ), scoring significantly higher on the AIHQ-Anger Bias and the AIHQIntentionality Bias subscales $[38,45]$. Patients with subthreshold depressive symptoms had higher anger bias and aggression bias scores [38,53]. Lahera et al. [38] found that hostile intent attribution and blame attribution was related to depressive symptoms [38]. A correlation between social functioning and attributional style was found in both studies. GAF correlated negatively with intentionality [38,53], anger, and aggression biases [53]. Functioning also correlated significantly with attributional style and attributional bias [53]. Among euthymic patients, significant bivariate correlations were found between the GAF, Hamilton Depression Rating Scale (HDRS), AIHQ Total and AIHQ-Intentionality scores. A regression analysis in a subsample of patients with subsyndromal depressive symptoms showed that the HDRS score and hostility bias were both strongly associated with social functioning [38].

Exploration of the empathy dimension showed that patients with BD scored lower on the Perspective Taking subscale and higher on the Personal Distress subscale than HC. There were significant positive correlations between the Interpersonal Reactivity Index (IRI) Personal Distress subscale, global social functioning, and the Work/School Role, Social/Leisure Activities, and Relationship with Extended Family domains of the SAS-SR. Moreover, individuals who scored lower on the IRI Empathic Concern subscale also showed reduced functioning in the Social/ Leisure Activities domain of the SAS-SR [57].

A study focusing on social perception found that the BD group performed significantly more poorly than the HC group, suggesting that individuals with $\mathrm{BD}$ make impaired judgments about everyday social situations. The Interpersonal Perception Task (IPT-15) Kinship subscale was negatively correlated with the Marital Role domain of the SAS-SR. A significant negative association was also found between the IPT-15 Intimacy subscale and the SAS-SR Work/School Role domain. Moreover, the BD group scored lower than controls on the IPT-15 Kinship and Competition subscales. No significant group differences were found for the IPT15 Intimacy, Status, and Deception subscales [54].

\section{Discussion}

The present literature review was conducted to collate the data available on interactions between functional outcome and social cognition in $\mathrm{BD}$. In the 20 available studies, five social cognitive domains were considered: ToM (both emotional and cognitive), emotion processing, attributional bias, empathy, and social perception. Overall, significant correlations were found between all the social cognitive domains and social functioning.

The ability to identify emotion in other people is critical to social functioning. The majority of the studies revealed a link between social functioning and emotion processing (recognition, discrimination, regulation) in euthymic and symptomatic patients with $\mathrm{BD}$. In the case of facial emotion recognition, three emotions (happiness, fear and disgust) were found to be significantly correlated with functional impairment in BD. Happiness was the emotion least subject to errors in emotion recognition [49]. Among patients with schizophrenia, the ability to recognize emotions has been shown to have no direct effect on social interaction in real life [58], but patients who erroneously report recognizing relatively high levels of happiness function better socially and have less severe symptoms [59]. Fear recognition was also associated with impaired social functioning in two studies $[40,50]$. Regarding the third emotion, our review revealed that difficulty recognizing the disgust emotion is related to poorer social functioning in the BD population. Similarly, in the schizophrenia literature, the recognition of disgust is significantly associated with functioning. A positive correlation was found in one study between correct recognition of disgust and patients' social and professional functioning [60]. There are functional domains for which correct recognition of disgust may be particularly important, such as social and professional interactions. Recognizing it may allow patients to adapt their responses, and may lead them to move toward more socially accepted behaviors [60]. Emotion regulation, and managing and understanding emotions were also correlated with social functioning $[51,52,61]$. Emotion regulation was associated with subjective and objective psychosocial functioning, while understanding and managing emotions was associated with the autonomy, occupational and relationship domains. Even though emotion processing explains part of the variance of social functioning, this relationship between emotion processing and functional outcomes seemed to be modulated by depressive symptoms [38,45,48,51,53,61]. More than half the studies included patients who either had subsyndromal symptoms or were in a depressive state. When depressive symptomatology was included in the statistical analysis (correlation or regression analysis), the association between emotion processing and social functioning became weaker. Van Rheenen and Rossell [39] demonstrated a mediation effect of depression symptomatology on emotion regulation and subjective and objective psychosocial functioning in BD. It should be noted that in the majority of studies, patients had more subyndromal depressive symptoms than depressive states. The link between psychosocial disabilities and the severity of affective symptoms has already been reported in the literature [62-64]. Not only depressive episodes, but also subsyndromal levels, have been shown to be strongly associated with poor social functioning. For example, Simon et al. [11] found that even subtle changes in the severity of depression were associated with statistically significant changes in functional impairment and disability. As suggested by Van Rheneen et al.'s analysis, mood symptoms may be a mediator between emotion processing and social functioning. On the other hand, poor social functioning during depression might also be mediated by the domains proposed by Pulcu and Elliott [65], including emotion processing. Their hypothesis is that emotion processing and social perception, motivation and reward value processing and social decision making constitute the fundamental sequential stages of social interactions [65]. In this hypothesis, emotion processing exploration should be included in experimental tasks, integrated with the other domains, for a higher ecological validity and a better understanding of social functioning variability. However, three studies did not find any effect of depressive symptoms [40,47,50]. Only one study directly compared the emotion recognition and 
discrimination performances of patients with BD across the different phases of the disease. This showed that during mood remission, accurate emotion discrimination has a positive effect on participation in social and daily activities and hobbies, while correct emotion identification has a positive impact on taking initiatives and feeling self-sufficient [43]. In both depressive and manic episodes, no significant correlation was found between emotion processing and the domains of social functioning [43]. Although the majority of studies highlighted an effect of depressive symptoms on the link between social cognition and social functioning, several studies failed to find one. Further research using a methodology similar to that featured in Aydemir et al.'s study is needed to clarify this aspect.

For ToM, results were more discrepant, with only three of the 12 relevant studies finding a significant relationship between ToM scores (RMET and the Faux Pas test) and functional impairment. Two of these studies found an association between ToM scores and functional outcomes, as assessed by the GAF. The third study reported an association with the social functional domains of home duties and work duties. The one study to assess the impact of clinical symptomatology found an influence of subsyndromal depressive symptomatology on the relationship between verbal social cognition and social functioning. Both the RMET, a mentalstate decoding task, and the Faux Pas test are regarded as affective ToM tests [66]. They revealed affective ToM impairments that significantly correlated with poorer functioning in BD. The other ToM tasks probe reasoning on cognitive mental states. One plausible explanation for the weaker correlation between cognitive ToM and functioning lies in the crucial differences between affective and cognitive ToM tasks. These constructs are theoretically distinct, in that the former involves noticing something about what another person is experiencing (e.g., recognizing possible emotions in others), while the latter involves forming ideas about others' intentions and goals [67]. Shamay-Tsoory et al. [68] suggested that affective and cognitive ToM have different neural bases. Until recently, no definite conclusions could be drawn about ToM impairments in $\mathrm{BD}$, as results were sometimes contradictory. However, in a recently published meta-analysis, Bora et al. [18] found that patients with BD exhibited significant impairment on all ToM tasks, regardless of which ToM domain was being evaluated (affective/cognitive or verbal/visual). The ToM deficit was present regardless of mood state, but was significantly more severe during acute episodes. A recent study focusing on the connection between persecutory delusions and impaired functioning in schizophrenia hypothesized that causality is reversed, and an impoverished social life leads to poorer ToM rather than vice versa [67]. This could also apply to BD, given that we did not found a strong causal relation. In addition, based on the presence of partial correlations within the results, we can hypothesize that antipsychotic medication may influence the association between ToM performance and social functioning in patients with BD. The effect of antipsychotics on ToM performance has already been considered, but with inconclusive results [69-71]. ToM measures may also be too limited and possibly not sufficiently specific to reveal links with functional impairment among patients with BD.

No significant association was found between manic symptomatology itself and either social functioning or social cognition. This lack of an association may be due to methodological limitations. For a start, in the studies included in this review, very few patients had hypomanic or manic symptoms, making comparisons difficult. The majority of social functioning scales are self-report measures. At a clinical level, we can assume that most social functioning scales require patients to have sufficient insight to notice and report their functioning impairments, and this insight is frequently lacking during manic states. Moreover, these scales may not be appropriate for individuals with BD who are experiencing manic episodes. They essentially assess the lack of social interactions and social activities, rather than excessive behaviors. Similarly, the social cognition tasks used are perhaps not the most appropriate. The majority of social cognition tasks used in the literature was designed to assess these processes in individuals with schizophrenia or autism, who have significant impairments in this domain. Like social functioning scales, social cognition tasks are more sensitive to the lack of affective and cognitive inferences. Studies seem to show that social cognitive impairments are less severe in BD than in schizophrenia [72]. These tasks possibly fail to highlight the social cognitive difficulties of patients in manic states, even though they influence functional outcomes.

Some of the limitations of our review are inherent to the review procedure, such as the heterogeneity of the BD samples across the different studies or the heterogeneity of the social cognition tasks they used. In the 20 studies we included, 23 different social cognition tasks were used (12 tasks for emotion processing, eight for ToM). The types of scales used to assess social functioning also constitute a methodological limitation. Most studies used the GAF or the FAST. The GAF score is a measure of general functioning more than a measure of social functioning. When the FAST scale was used, subdimensions were not always analyzed. Some aspects of social cognition may be more closely related to certain aspects of social functioning, as suggested by the results of Aydemir et al., who used a more comprehensive social functioning scale. More exhaustive scales are needed to address multiple aspects of function (e.g., SAS, work performance). The schizophrenia literature focuses on a more specific link between social cognition and social functioning [24]. It is important to understand the specificity of the associations between social cognition and social function versus other domains of function. The heterogeneity of results may also come from the mood dimension, as we included studies regardless of mood state. It would be interesting to conduct a further review that separately assessed manic, depressive and euthymic patients. In order to conduct such a review, more studies are needed, especially on the manic phase. In addition, studies of the link between social functioning and social cognition are needed to compare patients with different subtypes of BD (BD-I, BD-II, rapid-cycling). Two studies included in this review found no differences between BD-I and BD-II on social cognition tasks, but did not carry out separate analyses for the link with social functioning [47,50]. A recent meta-analysis of Bora [73] tried to distinguish different clinical subgroups of BD (type I vs. II and history of psychosis) to explore neurocognitive features and found only subtle and not distinctive differences between groups. Most of the cognitive heterogeneity in BD cannot be explained by the proposed subtypes of BD [73] and more studies are needed to adequately distinguish pertinent subgroups. The small number and the cross-sectional design of the studies we included may also restrict the generalizability of our review. Even so, the number of studies included is in line with the literature on these topics in BD [74]. Little is known in the literature about the effects of psychotropic drugs on social cognition, and additional information would be of interest [69]. Moreover, since the available literature points to the potential relevance of attentional and executive functioning to emotion processing in patients with BD [50], the generalized use of a uniform neuropsychological battery, such as the International Society for Bipolar Disorders-Battery for Assessment of Neurocognition (ISBD-BANC) [75] could be particularly useful for acquiring an overall cognitive perspective. Finally, despite the evidence that social cognition is a determinant of daily functioning in $\mathrm{BD}$, many of the relevant studies only carried out correlational analyses. Unfortunately, the results of such studies do not provide any information about the directionality of 
relationships, and explanatory models of associations remain heterogeneous and need to be developed [76].

\section{Conclusions}

Our review suggests that impaired functioning in the BD population is associated with social cognition deficits, especially in the domain of emotion processing. ToM results in the literature are more discrepant, reflecting the heterogeneity of the tasks and, possibly, of the processes involved. The involvement of mood state also deserves to be analyzed further, as depressive symptoms may mediate or moderate the relationship we found between social cognition and functioning. Further studies should be conducted in this specific area to understand the role of social cognition in social functioning and, possibly, to improve quality of life through social cognition training [77].

\section{Disclosure}

The authors declare that they have no conflicts of interest affecting this article.

This research received no specific grant from any funding agency, in either the commercial or not-for-profit sectors.

\section{Acknowledgements}

The authors thank all the people who took part in this study and Elizabeth Portier for reviewing the English style.

\section{References}

[1] Moreira A.L.R., Van Meter A, Genzlinger J, Youngstrom EA. Review and metaanalysis of epidemiologic studies of adult bipolar disorder. J Clin Psychiatry 2017;78(9):e1259-69.

[2] García López A, Ezquiaga E, de Dios C, Agud JL, Soler B. Retraso diagnístico y diferencias por sexo y subtipo clónico en una cohorte de pacientes ambulatorios con trastorno bipolar. Rev Psiquiatr Salud Ment 2010;79-89.

[3] Huxley N, Baldessarini RJ. Disability and its treatment in bipolar disorder patients. Bipolar Disord 2007;9(1-2):183-96.

[4] Bauwens F, Pardoen D, Staner L, Dramaix M, Mendlewicz J. Social adjustment and the course of affective illness: a one-year controlled longitudinal study involving bipolar and unipolar outpatients. Depress Anxiety 1998;8(2):50-7.

[5] Sanchez-Moreno J, Martinez-Aran A, Tabars-Seisdedos R, Torrent C, Vieta E, Ayuso-Mateos JL. Functioning and disability in bipolar disorder: an extensive review. Psychother Psychosom 2009;78(5):285-97.

[6] MacQueen GM, Young LT, Joffe RT. A review of psychosocial outcome in patients with bipolar disorder. Acta Psychiatr Scand 2001;103(3):163-70.

[7] Levy B, Manove E. Functional outcome in bipolar disorder: the big picture. Depress Res Treat 2012;2012:949248.

[8] Rosa AR, Bonnn CM, Vzquez GH, Reinares M. Sol Functional impairment in bipolar II disorder: is it as disabling as bipolar I? J Affect Disord 2010;127 (1):71-6.

[9] Lima F, Czepielewski L, Gama C, Kapczinski F, Rosa A. Cognitive and psychosocial impairment in remitted bipolar patients. Psicodebate 2014;14(2):25-38.

[10] Martino DJ, Marengo E, Igoa A, Scpola M, Ais ED, Perinot L, et al. Neurocognitive and symptomatic predictors of functional outcome in bipolar disorders: a prospective 1 year follow-up study. J Affect Disord 2009;116(1):37-42.

[11] Simon GE, Bauer MS, Ludman EJ, Operskalski BH, Untzer J. Mood symptoms, functional impairment, and disability in people with bipolar disorder: specific effects of mania and depression. J Clin Psychiatry 2007;68(8):1237-45.

[12] Burdick KE, Goldberg JF, Harrow M. Neurocognitive dysfunction and psychosocial outcome in patients with bipolar I disorder at 15-year followup. Acta Psychiatr Scand 2010;122(6):499-506.

[13] Torres IJ, DeFreitas CM, DeFreitas VG, Bond DJ, Kunz M, Honer WG, et al. Relationship between cognitive functioning and 6-month clinical and functional outcome in patients with first manic episode bipolar I disorder Psychol Med 2011;41(5):971-82.

[14] Martinez-Aran A, Vieta E, Colom F, Torrent C, Sanchez-Moreno J, Reinares M, et al. Cognitive impairment in euthymic bipolar patients: implications for clinical and functional outcome. Bipolar Disord 2004;6(3):224-32.

[15] Ochsner KN, Lieberman MD. The emergence of social cognitive neuroscience. Am Psychol 2001;56(9):717-34.

[16] Amodio DM, Frith CD. Meeting of minds: the medial frontal cortex and social cognition. Nat Rev Neurosci 2006;7(4):268-77.

[17] Green MF, Penn DL, Bentall R, Carpenter WT. Social cognition in schizophrenia: an NIMH workshop on definitions, assessment, and research opportunities. Schizophr Bull 2008;34(6):1211-20.
[18] Bora E, Bartholomeusz C, Pantelis C. Meta-analysis of Theory of Mind (ToM) impairment in bipolar disorder. Psychol Med 2016;46(02):253-64.

[19] Samamé C, Martino DJ, Strejilevich SA. Social cognition in euthymic bipolar disorder: systematic review and meta-analytic approach. Acta Psychiatr Scand 2012;125(4):266-80.

[20] Bora E, Gken S, Kayahan B, Veznedaroglu B. Deficits of social-cognitive and social-perceptual aspects of theory of mind in remitted patients with schizophrenia. J Nerv Ment Dis 2008;196(2):95-9.

[21] Sprong M, Schothorst P, Vos E, Hox J, van Engeland H. Theory of mind in schizophrenia: meta-analysis. Br J Psychiatry 2007;191:5-13.

[22] Pousa E, Duñó R, Brébion G, David AS, Ruiz AI, Obiols JE. Theory of mind deficits in chronic schizophrenia: evidence for state dependence. Psychiatry Res 2008;158(1):1-10.

[23] Mehta UM, Thirthalli J, Bhagyavathi HD. Similar and contrasting dimensions of social cognition in schizophrenia and healthy subjects. Schizophr Res 2014; 157(1):70-7.

[24] Couture SM, Penn DL, Roberts DL. The functional significance of social cognition in schizophrenia: a review. Schizophr Bull 2006;32(October (Suppl. 1)):S44-63.

[25] Green MF, Horan WP, Lee J. Social cognition in schizophrenia. Nat Rev Neurosci 2015;16(10):620-31.

[26] Moher D, Liberati A, Tetzlaff J, Altman DG. Preferred reporting items for systematic reviews and meta-analyses: the PRISMA statement. J Clin Epidemiol 2009;62(10):1006-12.

[27] Baron-Cohen S, Wheelwright S, Hill J, Raste Y, Plumb I. The « Reading the Mind in the Eyes " Test revised version: a study with normal adults, and adults with Asperger syndrome or high-functioning autism. J Child Psychol Psychiatry 2001;42(2):241-51.

[28] Baron-Cohen S, O’Riordan M, Jones R, Stone V, Plaisted K. A new test of social sensitivity: detection of faux pas in normal children and children with Asperger syndrome. J Autism Dev Disord 2016;29:407-18.

[29] American Psychiatric Association. Diagnostic and statistical manual of mental disorders. DSM-IV. 4th ed. Washington (DC): American Psychiatric Association; 1994.

[30] Rosa AR, Sanchez-Moreno J, Martinez-Aran A, Salamero M, Torrent C, Reinares M, et al. Validity and reliability of the Functioning Assessment Short Test (FAST) in bipolar disorder. Clin Pract Epidemiol Ment Health 2007;3(1):1-8.

[31] Weissman MM, Bothwell S. Assessment of social adjustment by patient selfreport. Arch Gen Psychiatry 1976;33(9):1111.

[32] Aas IHM. Collecting information for rating Global Assessment of Functioning (GAF): sources of information and methods for information collection. Curr Psychiatry Rev 2014;10(4):330-47.

[33] Altshuler L, Mintz J, Leight K. The Life Functioning Questionnaire (LFQ): a brief, gender-neutral scale assessing functional outcome. Psychiatry Res 2002;112 (2):161-82.

[34] Morosini PL, Magliano L, Brambilla L, Ugolini S, Pioli R. Development, reliability and acceptability of a new version of the DSM-IV Social and Occupational Functioning Assessment Scale (SOFAS) to assess routine social functioning. Acta Psychiatr Scand 2000;101(4):323-9.

[35] Aydemir O, Eren I, Savas H, Kalkan Oguzhanoglu N, Kocal N, Devrimci Ozguven $\mathrm{H}$, et al. Development of a questionnaire to assess inter-episode functioning in bipolar disorder: Bipolar Disorder Functioning Questionnaire. Turk Psikiyatri Derg 2007;18(4):344-52.

[36] Michalak EE, Murray G. Development of the QoL.BD: a disorder-specific scale to assess quality of life in bipolar disorder. Bipolar Disord 2010;12(7):727-40.

[37] Harper A, Power M. Development of the World Health Organisation WHOQOLBREF quality of life assessment. Psychol Med 1998;28(3):551-8.

[38] Lahera G, Herrera S, Reinares M, Rullas BA. Hostile attributions in bipolar disorder and schizophrenia contribute to poor social functioning. Acta Psychiatr Scand 2015;131:472-82.

[39] Van Rheenen TE, Rossell SL. Objective and subjective psychosocial functioning in bipolar disorder: an investigation of the relative importance of neurocognition, social cognition and emotion regulation. J Affect Disord 2014;162:134-41.

[40] Fulford D, Peckham AD, Johnson K, Johnson SL. Emotion perception and quality of life in bipolar I disorder. J Affect Disord 2013;152-154:491-7.

[41] Caletti E, Paoli RA, Fiorentini A, Cigliobianco M, Zugno E, Serati M, et al. Neuropsychology, social cognition and global functioning among bipolar, schizophrenic patients and healthy controls: preliminary data. Front Hum Neurosci 2013;17(7):661.

[42] Barrera A, Vázquez G, Tannenhaus L, Lolich M, Herbst L. Theory of mind and functionality in bipolar patients with symptomatic remission. Rev Psiquiatr Salud Ment 2013;6(2):67-74.

[43] Aydemir O, Akkaya C, Uykur B, Erol A. Effect of facial emotion recognition on subjective psychosocial functioning in bipolar patients. Acta Psychiatr Scand 2013;127(5):412-3.

[44] Vierck E, Joyce PR. Influence of personality and neuropsychological ability on social functioning and self-management in bipolar disorder. Psychiatry Res 2015;229(3):715-23.

[45] Lahera G, Ruiz-Murugarren S, Iglesias P, Ruiz-Bennasar C, Herrera E, Montes JM, et al. Social cognition and global functioning in bipolar disorder. J Nerv Ment Dis 2012;200:135-41.

[46] Wegbreit E, Weissman AB, Cushman GK, Puzia ME, Kim KL, Leibenluft E, et al. Facial emotion recognition in childhood-onset bipolar I disorder: an evaluation of developmental differences between youths and adults. Bipolar Disord 2015; 17:471-85. 
[47] Benito A, Lahera G, Herrera S, Muncharaz R, Benito G, Fernandez-Liria A, et al. Deficits in recognition, identification, and discrimination of facial emotions in patients with bipolar disorder. Rev Bras Psiquiatr 2013;35(4):435-8.

[48] Yalcin-Siedentopf N, Hoertnagl CM, Biedermann F, Baumgartner $S$, Deisenhammer EA, Hausmann A, et al. Facial affect recognition in symptomatically remitted patients with schizophrenia and bipolar disorder. Schizophr Res 2014;152:440-5.

[49] Hoertnagl CM, Muehlbacher M, Biedermann F, Yalcin N, Baumgartner S, Schwitzer G, et al. Facial emotion recognition and its relationship to subjective and functional outcomes in remitted patients with bipolar I disorder. Bipolar Disord 2011:13(5-6):537-44.

[50] Martino DJ, Strejilevich SA, Fassi G, Marengo E, Igoa A. Theory of mind and facial emotion recognition in euthymic bipolar I and bipolar II disorders. Psychiatry Res 2011;189(3):379-84.

[51] Aparicio A, Santos JL, Jimenez-Lopez E, Bagney A, Rodriguez-Jimenez R, Sanchez-Morla EM. Emotion processing and psychosocial functioning in euthymic bipolar disorder. Acta Psychiatr Scand. 2017;135(4)339-50 avr.

[52] Varo C, Jimenez E, Sole B, Bonnin CM, Torrent C, Valls E, et al. Social cognition in bipolar disorder: focus on emotional intelligence. J Affect Disord 2017;217:210-7.

[53] Lahera G, Benito A, González-Barroso A, Guardiola R, Herrera S, Muchada B, et al. Social-cognitive bias and depressive symptoms in outpatients with bipolar disorder. Depress Res Treat 2012;2012:1-6.

[54] Cusi AM, Macqueen GM, McKinnon MC. Patients with bipolar disorder show impaired performance on complex tests of social cognition. Psychiatry Res 2012;200(2-3):258-64.

[55] Purcell AL, Phillips M, Gruber J. In your eyes: does theory of mind predict impaired life functioning in bipolar disorder? J Affect Disord 2013;151 (3):1113-9.

[56] Olley AL, Malhi GS, Bachelor J, Cahill CM, Mitchell PB, Berk M. Executive functioning and theory of mind in euthymic bipolar disorder. Bipolar Disord 2005;7(Suppl. 5):43-52.

[57] Cusi A, Macqueen GM, McKinnon MC. Altered self-report of empathic responding in patients with bipolar disorder. Psychiatry Res 2010;178:354-8.

[58] Janssens M, Lataster T, Simons CJP, Oorschot M, Lardinois M, van Os J, et al. Emotion recognition in psychosis: no evidence for an association with real world social functioning. Schizophr Res 2012;142(1):116-21.

[59] Cohen AS, Nienow TM, Dinzeo TJ, Docherty NM. Attribution biases in schizophrenia: relationship to clinical and functional impairments. Psychopathology 2009;42(1):40-6.

[60] Hofer A, Benecke C, Edlinger M, Huber R, Kemmler G, Rettenbacher MA, et al. Facial emotion recognition and its relationship to symptomatic, subjective, and functional outcomes in outpatients with chronic schizophrenia. Eur Psychiatry 2009;24(1)27-32 janv.

[61] Van Rheenen TE, Rossell SL. Phenomenological predictors of psychosocia function in bipolar disorder: is there evidence that social cognitive and emotion regulation abnormalities contribute? Aust N Z J Psychiatry 2014;48 (1):26-35.
[62] Kauer-Sant'Anna M, Kapczinski F, Andreazza AC, Bond DJ, Lam RW, Young LT, et al. Brain-derived neurotrophic factor and inflammatory markers in patients with early- vs. late-stage bipolar disorder. Int J Neuropsychopharmacol 2009;12(4):447-58.

[63] Tabars-Seisdedos R, Balanz-Martnez V, Snchez-Moreno J, Martinez-Aran A, Salazar-Fraile J, Selva-Vera G, et al. Neurocognitive and clinical predictors of functional outcome in patients with schizophrenia and bipolar I disorder at one-year follow-up. J Affect Disord 2008;109(3):286-99.

[64] Rosa AR, Reinares M, Franco C, Comes M, Torrent C, Snchez-Moreno J, et al. Clinical predictors of functional outcome of bipolar patients in remission. Bipolar Disord 2009;11(4):401-9.

[65] Pulcu E, Elliott R. Neural origins of psychosocial functioning impairments in major depression. Lancet Psychiatry 2015;2(9):835-43.

[66] Shamay-Tsoory SG, Shur S, Barcai-Goodman L, Medlovich S, Harari $H$ Levkovitz Y. Dissociation of cognitive from affective components of theory of mind in schizophrenia. Psychiatry Res 2007;149(1):11-23.

[67] Phalen PL, Dimaggio G, Popolo R, Lysaker PH. Aspects of Theory of Mind that attenuate the relationship between persecutory delusions and social functioning in schizophrenia spectrum disorders. J Behav Ther Exp Psychiatry 2016;56:65-70.

[68] Shamay-Tsoory SG, Aharon-Peretz J. Dissociable prefrontal networks for cognitive and affective theory of mind: a lesion study. Neuropsychologia 2007;45(13):3054-67.

[69] Kucharska-Pietura K, Mortimer A. Can antipsychotics improve social cognition in patients with schizophrenia? CNS Drugs 2013;27(5):335-43.

[70] Mizrahi R, Korostil M, Starkstein SE, Zipursky RB, Kapur S. The effect of antipsychotic treatment on Theory of Mind. Psychol Med 2007;37(4):595.

[71] Sergi MJ, Green MF, Widmark C, Reist C, Erhart S, Braff DL, et al. Social cognition and neurocognition: effects of risperidone, olanzapine, and haloperidol. Am J Psychiatry 2007;164(10):1585-92.

[72] Bora E, Pantelis C. Social cognition in schizophrenia in comparison to bipolar disorder: a meta-analysis. Schizophr Res 2016;175(1):72-8.

[73] Bora E. Neurocognitive features in clinical subgroups of bipolar disorder: a meta-analysis. J Affect Disord 2018;229:125-34, doi:http://dx.doi.org/10.1016/ j.jad.2017.12.057.

[74] Duarte W, Becerra R, Cruise K. The relationship between neurocognitive functioning and occupational functioning in bipolar disorder: a literature review. Eur J Psychol 2016;12(4):659-78.

[75] Yatham LN, Torres IJ, Malhi GS, Frangou S, Glahn DC, Bearden CE, et al. The International Society for Bipolar Disorders-Battery for Assessment of Neurocognition (ISBD-BANC). Bipolar Disord 2010;12(4):351-63.

[76] Martinez-Dominguez S, Penades R, Segura B, Gonzalez-Rodriguez A, Catalan R. Influence of social cognition on daily functioning in schizophrenia: study of incremental validity and mediational effects. Psychiatry Res 2015;225(3):374-80.

[77] Tas C, Brown E, Cubukcuoglu Z, Aydemir O, Danaci AE, Brne M. Towards an integrative approach to understanding quality of life in schizophrenia: the role of neurocognition, social cognition, and psychopathology. Compr Psychiatry 2013;54(3):262-8. 